\title{
Short-term fitness benefits of physiological integration in the clonal herb Hydrocotyle peduncularis
}

\author{
ANDREW G. PETERSON* AND PETER CHESSON ${ }^{\dagger}$ \\ Research School of Biological Sciences, Institute of Advanced Studies, Australian National University, \\ Canberra, Australian Capital Territory, Australia
}

\begin{abstract}
We test whether physiological integration enhances the short-term fitness of the clonal herb Hydrocotyle peduncularis (Apiaceae, R. Brown ex A. Richards) subjected to spatial variation in water availability. Our measures of fitness and costs and benefits are based on the relative growth rate of fragmented genets. Physiological integration over a gradient in soil moisture resulted in a highly significant net benefit to genet growth of $0.015 \mathrm{~g} \mathrm{~g}^{-1} \mathrm{day}^{-1}$. This net benefit represents a significant enhancement of the average fitness of fragmented genets spanning the moisture gradient relative to the average of those growing in homogeneous moist or dry conditions. Sections of genet fragments growing in dry conditions in spatially heterogeneous treatments had significantly higher growth than the sections they were connected to that were growing in moist conditions. Within fragments, older (parent) sections growing in moist conditions experienced significant costs from connection to younger (offspring) sections growing in dry conditions. In contrast, offspring sections with ample water did not experience any costs when connected to parent sections growing in dry conditions. However, the net benefit of physiological integration was similar for parent and offspring sections, suggesting that parent and offspring sections contributed equally to the net benefit of physiological integration to genet growth and short-term fitness.
\end{abstract}

Key words: clonal growth, fitness, genet, physiological integration, spatial heterogeneity.

\section{INTRODUCTION}

In clonal plants, physiological integration among ramets connected by stolons or rhizomes may ameliorate the poor growth of ramets growing in relatively dry patches if they are connected to ramets in patches of higher soil moisture (Tietema \& van der Aa 1981; Salzman \& Parker 1985; Alpert \& Mooney 1986; Lau \& Young 1988; Evans 1991; Stuefer et al. 1994; de Kroon et al. 1996, 1998). An important, although often implicit idea in these and many other studies of clonal plants is that physiological integration will enhance the fitness of the genetic individual (the genet). We use the clonal herb Hydrocotyle peduncularis (Apiaceae, R. Brown ex A. Richards) to test the hypothesis that physiological integration enhances the average shortterm fitness of genets growing in environments with spatial variation in water availability relative to their average fitness in homogeneous moist and dry environments. In doing so, we apply a quantitative framework for assessing the effect of physiological integration on

${ }^{\star}$ Corresponding author. Present address: Department of Earth and Environmental Sciences, Columbia University, Biosphere 2 Center, 32540 South Biosphere Road, Oracle, Arizona 85623, USA (Email: apeterso@bio2.columbia.edu).

tPresent address: Section of Evolution and Ecology, Storer Hall, University of California, Davis, California, USA.

Accepted for publication May 2002. the fitness of clonal plants (Chesson \& Peterson, in press). This framework is based on the notion that the relative growth rate (RGR) of the genet, defined as the change in ln dry mass per unit time $\left(\mathrm{g} \mathrm{g}^{-1}\right.$ day $^{-1}$; Evans 1972), is an integrative measure of fitness in clonal organisms. The theory presented by Chesson and Peterson (in press) also shows that there are many subtleties in the study of physiological integration, indicating a need for special care in the analysis of physiological integration experiments if valid conclusions about fitness benefits are to be made. Two of the more important of these subtleties are the potential for falsely identifying a net benefit of physiological integration when in fact physiological integration is absent, and the time dependency of the net benefit of physiological integration. The quantitative framework used here allowed us to assess these two potential sources of error in our evaluation of the fitness benefits of physiological integration.

Another benefit that comes from the use of the RGR as the basis for analysing experiments on physiological integration is an important increase in the precision of the analysis because of the RGR correcting for initial plant mass and time. This increase in precision does not depend on the plant being in a phase of exponential growth. If growth is not exponential, the only limitation to the use of the RGR is that predictions based on times that are shorter or longer than used in the experiment cannot be made. 


\section{Measuring fitness in clonal plants}

Fitness is fundamentally the rate at which zygotes produce new zygotes (Harper 1985) and is frequently quantified using $r$, the instantaneous per capita rate of increase (Stearns 1992). In clonal plants, fitness is a function of both genet and ramet dynamics (Sackville Hamilton et al. 1987): genet dynamics because of sexual reproduction (Harper 1981; Pitelka \& Ashmun 1985; Eriksson \& Jerling 1990), and ramet dynamics because these modules are the source of totipotent meristems from which the genome is replicated, both vegetatively and sexually (Buss 1985; Caswell 1985; Sibly 1989; Fagerström 1992; Wikberg 1995).

Pedersen and Tuomi (1995) emphasize that natural selection may act on the hierarchical levels of both the genet and the ramet, but in many clonal plant systems it is impractical to measure fitness in terms of genet dynamics because of the relative rareness of seedling recruitment (Eriksson 1989; Nault \& Gagnon 1993; Shimizu et al. 1998) and the potential for genets to be extraordinarily long-lived (Cook 1985). Importantly, the rareness of seedling recruitment relative to ramet recruitment lends weight to the argument that the rate of production of new ramets may dominate genet fitness. Moreover, in situations where the number of ramets is a good predictor of seed production, a rametbased measure of fitness is sufficient, as proven by its extensive use in models of evolutionary demography (Caswell 1985; Nault \& Gagnon 1993; Silvertown et al. 1993; Carlsson \& Callaghan 1994; Okland 1995; Pedersen 1995; Wikberg 1995; Erschbamer et al. 1998; Shimizu et al. 1998). Such a measure might be improved by taking account of ramet size, because this is positively correlated with survival, ramet production and sexual reproductive capacity in clonal plants (Newell et al. 1981; Hutchings 1983; Goldberg 1988; Nault \& Gagnon 1993; Okland 1995; Worley \& Harder 1996; Cain \& Damman 1997; Hara \& Herben 1997; Laterra et al. 1997; Wijesinghe \& Whigham 1997; Mendoza \& Franco 1998; Piqueras \& Klimes 1998). Modifying a ramet-based $r$ as the measure of fitness gives the RGR of the genet, as defined previously herein. Indeed, the RGR of the genet is recognized as a fundamental component of fitness in colonial ascidians (Stoner 1989).

Because the genet is the genetic individual, it is the RGR of the entire genet that should be estimated in experimental studies of clonal plant fitness. In general, this requirement will mean combining biomasses over fragmented parts of a genet that is distributed over a spatially heterogeneous environment. Such considerations naturally lead to questions of how different parts of a genet, experiencing different conditions, contribute to genet growth, and how physiological connections between parts of a genet may affect such contributions. We define genet fragments as groups of ramets con- nected by stolons or rhizomes. Physiological integration may occur within a fragment but it cannot occur between fragments because of the absence of physical connections. In addition, genet fragments can be divided into sections representing the older, or parent part of the fragment, and the younger, or offspring part.

Hydrocotyle peduncularis is a member of the herbaceous understorey of wet-sclerophyll Eucalyptus forests in south-eastern Australia. The evergreen Eucalyptus spp. drop large quantities of leaves and bark throughout summer (Keith 1991), and this litter can have a pronounced effect on soil moisture over small spatial scales. The gravimetric water content of soil in the rooting zone of $H$. peduncularis can vary by $25 \%$ over distances as small as $10 \mathrm{~cm}$ in response to variation in litter density (Peterson 1996). Physiological integration for water between sections of genet fragments located in patches of different moisture status may enhance the average fitness of genets if the benefits of integration to genet growth outweigh any associated costs.

\section{METHODS}

\section{Species}

Hydrocotyle peduncularis is a fast-growing perennial herb of low stature. It has a stoloniferous growth form with a monopodial branching pattern (regular branching from one primary axis) and stolons that persist throughout the year. Its leaves vary in shape from circular to cordate or reniform, and range in size from 5 to $15 \mathrm{~mm}$ in diameter, although plants growing in deep shade may have leaves more than $50 \mathrm{~mm}$ in diameter. Stolon length between ramets varies from $5 \mathrm{~mm}$ to more than $150 \mathrm{~mm}$. It is common for stolons to grow over other vegetation and obstacles, and for unrooted ramets to grow in these places.

\section{Design}

Experimental material was collected from nursery plants housed in glasshouse facilities at the Research School of Biological Sciences, The Australian National University, Canberra, Australia. The nursery plants were established from 10 ramets collected from a site in the Brindabella Ranges, approximately $60 \mathrm{~km}$ southwest of Canberra in the Australian Capital Territory $\left(148^{\circ} 50^{\prime} \mathrm{E}, 35^{\circ} 23^{\prime} \mathrm{S}\right.$, altitude $1040 \mathrm{~m}$ a.s.l., easterly aspect). These ramets were located at least $50 \mathrm{~m}$ apart in the field and were assumed to be genetically distinct individuals. In this experiment we did not control for genotype but instead attempted to obtain a represen- 
tative sample of genets from a local population. Our following statements therefore always refer to averages over genets, but for brevity we refer to 'genets' and 'the genet level' rather than 'averages over genets' or 'averages at the genet level'.

Experimental units were genet fragments consisting initially of pairs of ramets connected by a healthy intact stolon. All genet fragments were similar in terms of ramet size, root structure, number of leaves, and leaf area. The older ramet in each fragment is referred to as the parent ramet, which became the parent section with further growth; the younger ramet is referred to as the offspring ramet, which developed into the offspring section.

Each genet fragment was planted in a pair of rectangular plastic pots $(10.0 \mathrm{~cm}$ long $\times 8.5 \mathrm{~cm}$ wide $\times$ $4.0 \mathrm{~cm}$ deep) with one ramet in each pot. This arrangement isolated the root system of each ramet from that of its partner, preventing below-ground competition. Stolons were left intact to allow the transfer of material between ramets. Only the original ramet in a section was allowed to root and all new ramets and associated stolons were draped over the sides of the pot.

Each pot was filled with potting mix consisting of equal parts loam, washed river sand and peat. Soil moisture was maintained at field capacity using a cotton wick to conduct water to the soil from a reservoir. Waterlogging did not occur because the pots were free draining. All plants were arranged randomly on a glasshouse bench where they received natural light, and their positions were randomly rearranged once per week during the experiment. Plants were allowed 3 weeks to acclimate after replanting before treatments were applied.
We subjected genet fragments to different spatial patterns of water limitation. For brevity, the waterlimited sections are referred to as stressed and the other sections as unstressed. We use the symbol '+' to represent the unstressed condition and '-' the stressed condition following Stuefer et al. (1994). Equal numbers of genet fragments were collected from each nursery plant and allocated randomly to four treatment groups. The treatments were: (i) both parent and offspring sections of a fragment unstressed $(\mathrm{P}+\mathrm{O}+$, where $\mathrm{P}$ is the parent section and $\mathrm{O}$ the offspring section); (ii) both sections stressed (P-O-); (iii) only the parent section stressed $(\mathrm{P}-\mathrm{O}+)$; and (iv) only the offspring section stressed $(P+\mathrm{O}-)$. Each treatment group had five replicates.

Treatments were applied on 29 July 1992, and the experiment was terminated 21 days later. Sections that were to be stressed had their water reservoir drained. The water content of the low soil-moisture pots was controlled by using five individual ramets planted in separate pots (water controls) that were subjected to the same conditions as the stressed sections in the experimental units. These controls were weighed each evening to estimate the average mass of water lost through evapotranspiration during the day. This measure of evapotranspiration was used to calculate how much water needed to be added to these pots to return their average gravimetric soil-water content to approximately $15 \%$ above the permanent wilting point. This mass of water was then added to all low soilmoisture pots. The maximum gravimetric water content for the low soil-moisture treatment was set at $15 \%$ above the permanent wilting point because preliminary trials showed that growth of $H$.peduncularis

Table 1. Acronyms used in this paper and their description

\begin{tabular}{|c|c|}
\hline Acronym & Description \\
\hline RGR & Relative growth rate \\
\hline CRGR & Component relative growth rate; additive contribution of fragment sections to the RGR of the fragment \\
\hline NetBen & Net benefit of physiological integration \\
\hline NetBenP & Additive contribution to NetBen provided by the parent section \\
\hline $\mathrm{NetBenO}$ & Additive contribution to NetBen provided by the offspring section \\
\hline BenP & $\begin{array}{l}\text { Benefit to a stressed parent section from being connected to an unstressed offspring section; measured as a } \\
\text { change in CRGR }\end{array}$ \\
\hline CostP & $\begin{array}{l}\text { Cost to an unstressed parent section from being connected to a stressed offspring section; measured as a change } \\
\text { in CRGR }\end{array}$ \\
\hline $\mathrm{BenO}$ & $\begin{array}{l}\text { Benefit to a stressed offspring section from being connected to an unstressed parent section; measured as a } \\
\text { change in CRGR }\end{array}$ \\
\hline CostO & $\begin{array}{l}\text { Cost to an unstressed offspring section from being connected to a stressed parent section; measured as a change } \\
\text { in CRGR }\end{array}$ \\
\hline RMR & Root mass ratio; proportion of final fragment dry mass in roots \\
\hline SMR & Stem mass ratio; proportion of final fragment dry mass in stems \\
\hline LMR & Leaf mass ratio; proportion of final fragment dry mass in leaves \\
\hline CRMR & Component root mass ratio; proportion of final fragment dry mass in roots of the parent or offspring section \\
\hline CSMR & Component stem mass ratio; proportion of final fragment dry mass in stems of the parent or offspring section \\
\hline CLMR & Component leaf mass ratio; proportion of final fragment dry mass in leaves of the parent or offspring section \\
\hline CLR & Component leaf ratio; proportion of final fragment leaf area in the parent or offspring section \\
\hline
\end{tabular}


was limited at this level. This provided a safety margin against plant damage in the unlikely event that evapotranspiration was unexpectedly high during any particular day, while still maintaining a strong growth limitation.

Total leaf area, total stolon length, and total number of ramets were determined for each section immediately before the treatments were applied. These data were used to estimate the initial dry mass of each section from a previously determined multiple regression of $\ln$ transformed leaf area, stolon length, and number of offspring ramets against dry mass $\left(R^{2}=0.96\right)$. These variables were measured again at the end of the experiment and sections were harvested to determine the dry mass (constant mass at $80^{\circ} \mathrm{C}$ ) of leaves (including petioles), stems (including stolons) and roots.

\section{Analysis}

The experiment was set up as a standard two-factor balanced design. The first factor was the environment of the parent section and the second factor was the environment of the offspring section. Two-way ANOVA can therefore be applied to measurements on genet fragments. The standard hypotheses tested by two-way ANOVA, however, are not the most interesting from the perspective of physiological integration. We focus instead on using ANOVA to provide confidence intervals and significance tests for specific linear contrasts that are identified in Appendix I as measuring important aspects of physiological integration.

The most important contrasts involve the relative growth rate (see Table 1 for a full listing of acronyms and their descriptions) of genet fragments. In ANOVA terms, the contrast NetBen (equation 3, Appendix I) measures the interaction between the environments of the parent and offspring sections. As explained in Appendix I, it also measures the net benefit of physiological integration on short timescales.

Analyses of variance can also be done on component relative growth rates (CRGR) for parent and offspring sections (see Appendix I for definitions). The CRGR for sections within a fragment sum together to give the RGR of the fragment in a way that is analogous to partitioning the mass of a fragment into the separate masses of its sections. Because parent and offspring sections are not statistically independent, 'section' cannot be a factor in univariate ANOVA, but separate

Table 2. Two-way ANOva significance levels ( $P$ values) for the genet-fragment relative growth rate and biomass ratios

\begin{tabular}{lccc}
\hline \multirow{2}{*}{ Variable } & \multicolumn{2}{c}{ Main effects } & Interaction \\
& Parent section stressed & Offspring section stressed & Parent stressed $\times$ offspring stressed \\
\hline RGR & 0.122 & 0.048 & 0.007 \\
LMR & 0.961 & 0.864 & 0.070 \\
SMR & 0.042 & 0.005 & 0.051 \\
RMR & 0.011 & 0.001 & 0.014 \\
\hline
\end{tabular}

$F$-tests based on $n=5$ and d.f. $=1,16$. For definitions of acronyms see Table 1.

(a)

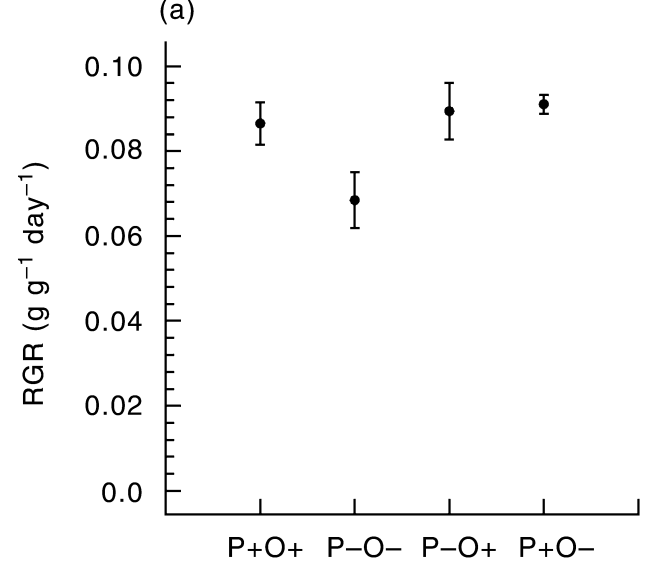

(b)

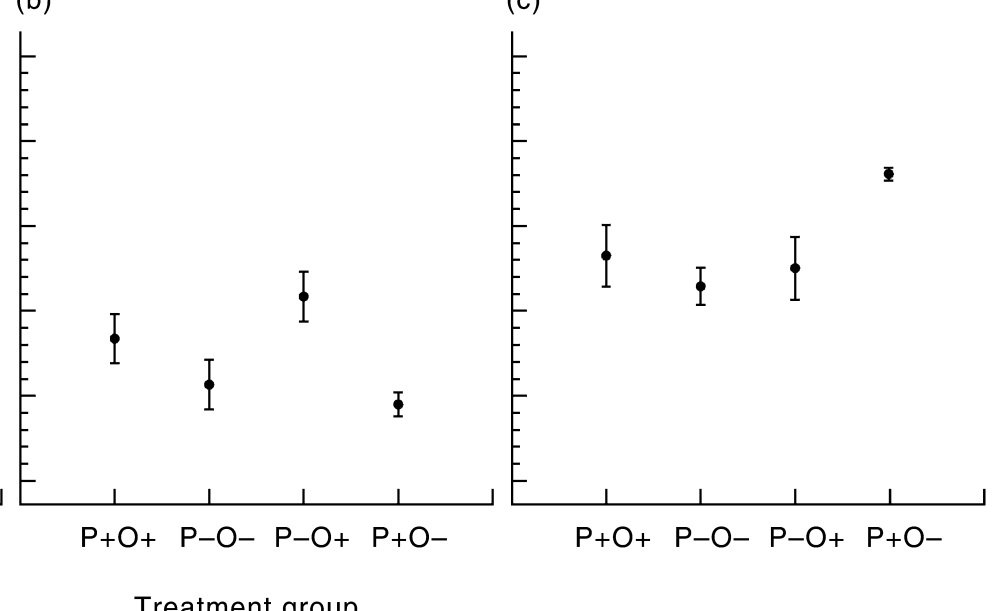

Fig. 1. (a) Mean $( \pm$ SEM) genet fragment relative growth rate (RGR) and component relative growth rates for the (b) parent sections and (c) offspring sections. Note that summing the component RGR values of the parent and offspring sections in each treatment group gives the genet fragment RGR for that group (see Appendix I for details). 
two-way ANOVA on parent sections, offspring sections and their difference are valid. These analyses provide tests and confidence intervals for the contrasts NetBenP and NetBenO (equations 11,12, Appendix I), which measure the separate contributions of parent and offspring sections to the overall net benefit (NetBen) of physiological integration. Measures of cost and benefit (CostP, BenP, etc., equations 7,8, Appendix I), and measures of symmetry between parent and offspring sections, are also linear contrasts in these analyses of variance. Tests of symmetry include a test of the grand mean (Lindman 1992) in the ANOVA of the difference between the CRGR of parent and offspring sections to identify whether any overall asymmetry appears when results for individual treatments are averaged over all treatment groups. Finally, ANOVA on costs and benefits calculated using relative growth rates (not component relative growth rates) for the parent and offspring sections of a genet fragment allows a test of the null hypothesis of no net benefit of physiological integration in the situation where genet fragments are not growing exponentially (contrast 13, Appendix I).

Patterns of biomass allocation to roots, stems and leaves were determined for genet fragments by calculating the root mass ratio (RMR), stem mass ratio (SMR) and leaf mass ratio (LMR) as the proportion of final fragment dry mass invested in each of these structures. Similarly, the component root mass ratio (CRMR), component stem mass ratio (CSMR) and component leaf mass ratio (CLMR) were calculated as the proportion of final fragment dry mass invested in each of these structures for the fragment's parent and offspring sections. The component leaf ratio (CLR) is the proportion of the fragment's final leaf area allocated to each of its sections.

All ANOVA and associated contrasts were calculated using the general linear hypothesis module of SYSTAT version 5.05 (Wilkinson 1992). Conformity with the assumptions of ANOVA was satisfactory in all cases.

Table 3. Cost-benefit analyses for the genet-fragment relative growth rate and component relative growth rates $\left(\mathrm{g} \mathrm{g}^{-1}\right.$ day $\left.^{-1}\right)$

\begin{tabular}{lc}
\hline Parameter & $\begin{array}{c}\text { Lower } 95 \% \mathrm{CI} \leq \text { mean } \leq \text { upper } \\
95 \% \text { confidence interval }\end{array}$ \\
\hline NetBen & $0.005 \leq 0.015 \leq 0.025$ \\
NetBenP & $-0.007 \leq 0.003 \leq 0.013$ \\
BenP & $0.007 \leq 0.021 \leq 0.035$ \\
CostP & $0.002 \leq 0.016 \leq 0.030$ \\
NetBenO & $0.001 \leq 0.012 \leq 0.023$ \\
BenO & $0.012 \leq 0.027 \leq 0.042$ \\
CostO & $-0.012 \leq 0.003 \leq 0.018$ \\
NetBenO-NetBenP & $-0.054 \leq-0.019 \leq 0.0156$ \\
\hline
\end{tabular}

Note that a net component-benefit (i.e. NetBenP and $N e t B e n O$ ) equals half the difference between the tabulated benefit and cost. For definitions of acronyms see Table 1 .

\section{RESULTS}

\section{Genet-fragment growth}

The RGR of genet fragments showed clear effects of water limitation, with the RGR of the $\mathrm{P}-\mathrm{O}-$ group being much lower than that in the other three groups (Table 2, Fig. 1a). The test of the null hypothesis of no physiological integration was significant $\left(F_{1,16}=6.731\right.$, $P=0.020)$, indicating that the relative growth rate of sections in the heterogeneous groups was dependent on the environments of their partners and that physiological integration between sections occurred. The interaction term (NetBen) comparing the average RGR of fragments experiencing homogeneous conditions with those experiencing heterogeneous conditions was highly significant (Table 2), with a net benefit of physiological integration equal to $0.015 \mathrm{~g} \mathrm{~g}^{-1} \mathrm{day}^{-1}$ (Table 3). The RGR of the $\mathrm{P}-\mathrm{O}+$ and $\mathrm{P}+\mathrm{O}-$ groups were similar in magnitude $(P=0.722)$, suggesting that the overall response of genets to heterogeneous conditions was not sensitive to whether the parent or offspring sections were stressed. Thus, the net benefit of physiological integration at the level of the genet does not appear to depend on the direction of translocation.

Time dependence of the net benefit of physiological integration was tested by applying a randomization test (Manly 1997; 5000 randomizations) to the correction term given by equation 4 of Appendix I. This correction, which estimates how much NetBen deviates from the exact time-dependent net benefit of physiological integration (equation 2, Appendix I), was small, negative and marginally non-significant (two-sided $P=0.062$ ). Although this may mean that the net benefit of physiological integration is dependent

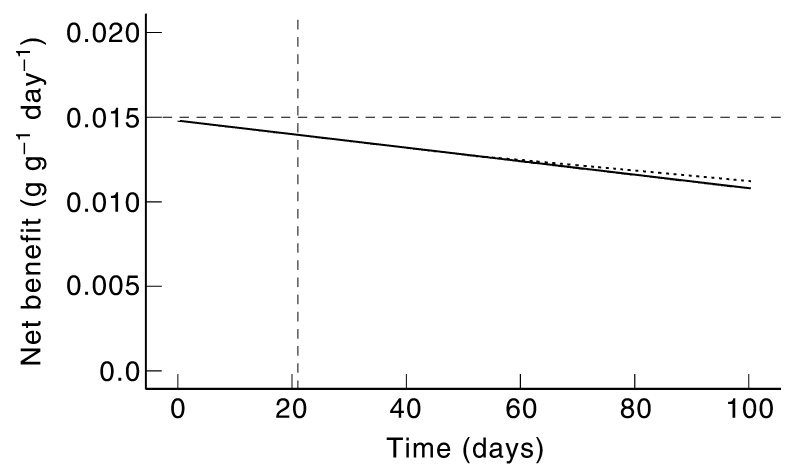

Fig. 2. Time series of the net benefit of physiological integration to genet growth. The horizontal dashed line is the value of NetBen which is independent of time, and the vertical dashed line marks the duration of this experiment. The dotted line is the time-dependent net benefit of physiological integration (equation 2, Appendix I). The solid line is NetBen plus the correction term (equation 4, Appendix I), which is an estimate of the time-dependent value. 
on time, the estimated correction term was only $-8.35 \times 10^{-4} \mathrm{~g} \mathrm{~g}^{-1}$ day $^{-1}$ by the end of the experiment. This amounts to just a $6 \%$ reduction in the estimated net benefit for 21 days compared with the instantaneous maximum rate estimated from these data. The effect of this correction is plotted in Fig. 2, along with the exact time-dependent net benefit of physiological integration. Note that although the correction term (expression 4 in the appendix) is just an approximation, it is quite accurate for these data. Also, because time-dependence is minimal, the uncorrected value of NetBen gives a satisfactory estimate of the net benefit of physiological integration over a time scale of several weeks.

\section{Additive contributions of parent and offspring sections to genet growth}

The mean CRGR of the offspring sections was higher than for the parent sections in all treatments, resulting in a highly significant grand mean effect for the CRGR difference (Table 4). This difference between parent and offspring sections was affected significantly by the stress state of each section (significant section main effects; Table 4). However, the interaction term, which tests $N e t B e n P=N e t B e n O$, was not significant (Table 4), providing no indication that parent and offspring sections contributed unequally to NetBen.

For both heterogeneous groups, stressing a section increased its additive contribution to fragment growth while reducing the contribution of its unstressed partner (significant section main effects; Table 4). Separate analyses of the parent and offspring section CRGR values showed that the highest values were in fact those of the stressed sections in the heterogeneous groups $\left(F_{3,16}=6.195, P=0.005\right.$ for the parent sections, Fig. $1 b ; F_{3,16}=5.930, P=0.006$ for the offspring sections, Fig. 1c).

Table 3 gives the breakdown of NetBen into sectional net benefits, NetBenP and NetBenO, which are broken down further into separate costs and benefits. For both parent and offspring sections, benefits (BenP and $\mathrm{BenO}$ ) were significantly positive. Costs were positive and smaller than benefits, resulting in positive values for NetBenP and NetBenO. CostO and NetBenP,

Table 4. Two-way ANOva significance levels ( $P$-values) for the difference between the offspring section and the parent section (offspring section - parent section) for component relative growth rates and component leaf and mass ratios. $F$-tests based on $n=5$ and d.f. $=1,16$

\begin{tabular}{lcccc}
\hline & & \multicolumn{2}{c}{ Main effects } & Interaction \\
Variable & Grand mean & $\begin{array}{c}\text { Parent section } \\
\text { stressed }\end{array}$ & $\begin{array}{c}\text { Offsping section } \\
\text { stressed }\end{array}$ & $\begin{array}{c}\text { Parent stressed } \times \text { offspring } \\
\text { stressed }\end{array}$ \\
\hline CRGR & $<0.001$ & 0.015 & 0.006 & 0.265 \\
CLR & $<0.001$ & 0.677 & 0.059 & 0.356 \\
CLMR & $<0.001$ & 0.283 & 0.090 & 0.238 \\
CSMR & $<0.001$ & 0.389 & 0.170 & 0.628 \\
CRMR & 0.131 & 0.012 & 0.002 & 0.651 \\
\hline
\end{tabular}

(a)

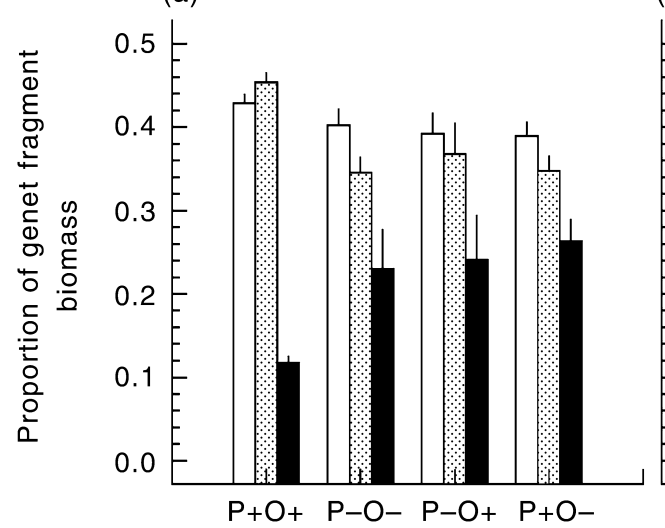

(b)

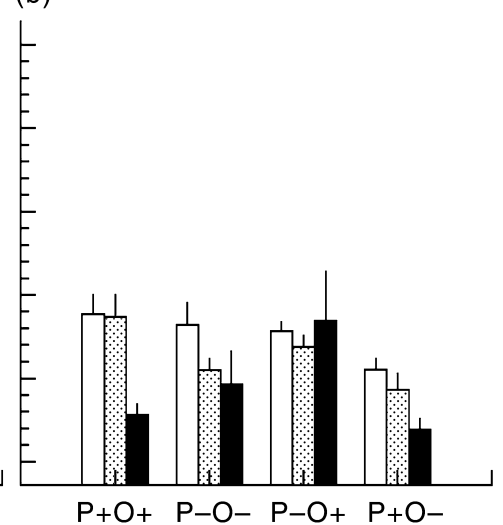

Treatment group (c)

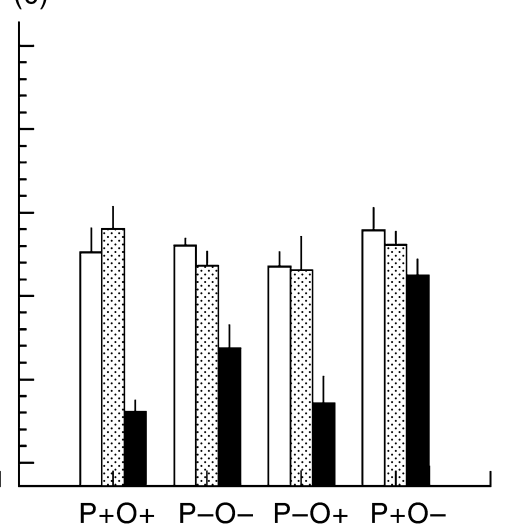

Fig. 3. (a) Mean $( \pm$ SEM) genet fragment mass ratios and component mass ratios for the (b) parent sections and (c) offspring sections. ( $\square$ ), Roots; (圆), stems; ( $\square$ ), leaves. Note that summing the component mass ratios of the parent and offspring sections in each treatment group gives the genet fragment mass ratio for that group. 
although positive, were not significantly different from zero. The fact that all other cost and benefit parameters in the table were significantly different from zero might be taken to mean that the cost-benefit structure for parent sections differed from that of offspring sections. However, the confidence intervals in the table all cover wide ranges, including those for $\mathrm{NetBenO}-\mathrm{NetBenP}$, meaning that there is little precision in such a comparison. Moreover, we noted previously that $\mathrm{NetBenO}$ was not significantly different from NetBenP, despite the fact that individually they differ in their significance from zero. Greater replication would be needed to clarify whether the cost-benefit structure of parent and offspring sections differ.

\section{Allocation patterns}

Proportional allocation of fragment biomass to parent sections was similar for all treatments at the start of the experiment $\left(F_{3,16}=0.236, P=0.870\right)$, and Bonferroni-adjusted pairwise comparisons failed to identify any significant differences in proportional allocation to parent sections at the end of the experiment. Therefore, changes in allocation to fragment sections are unlikely to have influenced our interpretations of NetBen and the cost-benefit structure for fragment sections in the present experiment.

Water limitation increased the allocation of fragment biomass to roots at the expense of allocation to stems with little effect on allocation to leaves (Table 2; Fig. 3a). Analysis of the difference between component ratios for offspring and parent sections (offspring section - parent section) showed that offspring sections had significantly greater fractions of fragment leaf mass, stem mass and leaf area than did the parent sections (significant grand mean effect; Table 4, Figs 3b,c). There was some suggestion that water limitation increased the CLR and CLMR for the offspring sections, but these effects were only significant at the 10\% level (offspring section main effect; Table 4). Averaging over all treatments showed that parent and offspring sections were similar in their contributions to fragment RMR (non-significant grand mean effect for CRMR; Table 4); however, in both heterogeneous groups, the stressed sections had greater CRMR values (significant section main effects; Table 4). Separate analyses of the parent and offspring section CRMR values showed that the highest values were in fact those of the stressed sections in the heterogeneous groups $\left(F_{3,16}=3.265, P=0.049\right.$ for the parent sections, Fig. $3 b ; F_{3,16}=12.839, P<0.001$ for the offspring sections, Fig. 3c). Previously it was noted that the fragment RMR was increased by limiting water to either section. These results for the component RMR values show a greater increase for stressed sections compared with their unstressed partners.

\section{DISCUSSION}

The presence of significant costs and benefits to sections in heterogeneous treatments demonstrates physiological integration between sections connected over a gradient in soil moisture. Moreover, these costs and benefits added up to a significant net benefit at the level of the genet, showing that physiological integration enhanced the average short-term fitness of $H$. peduncularis genets subjected to localized water limitation. Although there was some suggestion of asymmetry between parent and offspring sections for these costs and benefits, there was no significant difference in the contributions of parent and offspring sections to the net benefit at the level of the genet. In general, the offspring sections contributed more to fragment growth than did the parent sections, although this asymmetry may be due to the release of apical dominance in the offspring sections on account of their apical stolons being severed when fragments were removed from the nursery plants.

In both heterogeneous groups, water stress increased the additive contribution of the stressed sections to genet growth while reducing that of their unstressed partners. This demonstrates a major investment in the growth of the stressed sections in these groups. There are several possible explanations for this. The most likely is that neither the moist treatment nor the dry treatment were optimal for this species. Because growth responds non-linearly to increasing water availability, the treatments chosen in the present experiment may have fallen on either side of the optimum. In this scenario it is possible that the translocation of water from moist pots to dry pots in the heterogeneous treatments may have resulted in a near optimal supply of water to the sections in the dry pots. One way this could be facilitated is through hydraulic shift (de Kroon et al. 1996), where the difference in soil water potential between the moist and dry pots causes water to flow via the plant's vascular system from the soil in the moist pot to the soil in the dry pot during the night when the plant's stomates are closed. Hydraulic shift may provide additional water to that added experimentally to the dry pots, thus ameliorating the dry soil conditions in the heterogeneous groups during the night. This would represent a benefit of physiological integration under these conditions and has been observed in the clonal sedge Carex flacca when subjected to spatially variable water stress (de Kroon et al. 1996).

If the sections in the dry pots in the heterogeneous treatments were experiencing a more optimal supply of water and hence faster growth than the sections in the moist pots, then the faster growing sections may also have been sequestering other resources from, or competing with, the sections they were connected to (Novoplansky et al. 1989). Such competition may have resulted in the enhancement of the growth asymmetry 
seen in the $\mathrm{P}+\mathrm{O}-$ group. However, competition between sections may have been less important for the $\mathrm{P}-\mathrm{O}+$ treatment because of the large benefit to the stressed parent sections without any cost to the unstressed offspring sections. The negligible growth asymmetry observed in this group suggests that the resources sequestered from the unstressed sections may have been in excess of their own needs. This may represent a special case of an asymptotic relationship between growth and resource level (see Caraco \& Kelly 1991) when the resource level of the source section is at saturation. Depending on the nature of the nonlinear relationship, a source section at saturation could lose substantial amounts of resource to a sink partner with minimal detriment to its own growth. The movement of water between sections during the day in the presence of a non-linear response of plant growth to water availability and hydraulic shift at night may, independently or collectively, explain the enhanced growth of the stressed sections in both heterogeneous groups.

Water stress increased the proportion of fragment biomass invested in roots and reduced that invested in stems, irrespective of whether one or both sections in a fragment were stressed. This is a typical response of plants to medium-term water stress (Bradford \& Hsiao 1982), and is supported for clonal plants by Dale and Causton (1992) who found similar patterns of biomass allocation in the clonal species Veronica chamaedrys, V.montana and V.officinalis subjected to mild drought conditions. The treatments also affected the distribution of fragment biomass within and between sections. Stressed sections in both heterogeneous groups made greater relative contributions to fragment root mass than their unstressed partners. This response to localized water limitation is contrary to the division of labour hypothesis developed by Stuefer et al. (1996) and Alpert and Stuefer (1997), which predicts that fragments will allocate biomass to sections in a manner that will maximize uptake of the locally most abundant resource. Although allocation patterns suggestive of division of labour have been observed previously in clonal plants in response to spatial variation in water availability (Salzman \& Parker 1985; Evans \& Whitney 1992; de Kroon et al. 1996), the present experiment clearly demonstrates that the response of $H$. peduncularis was similar to that of unitary plants, that is, fragments allocated biomass to sections in a manner that maximized uptake of the locally most limiting resource.

The results of the present experiment have important implications for our understanding of the ecology of $H$. peduncularis and the implications of physiological integration in clonal plants. First, physiological integration can significantly enhance the average short-term fitness of $H$.peduncularis genets subjected to spatial variation in water availability. This fitness benefit exists even when some sections of genet fragments experience significant costs in terms of growth. Second, several new hypotheses come from these findings in association with theory developed in Chesson and Peterson (in press). Two of the most interesting hypotheses regard the time dependency of the net benefit of physiological integration. The first hypothesis is that the net benefit of physiological integration will decrease with time under fixed environmental conditions. The theory implies that ultimately the net benefit may disappear or even become a net cost, but in this experiment we found the rate of this decrease to be slow. This suggests that a net benefit of physiological integration may be realized for an extended period of time in this system even though the magnitude of that benefit may decrease with time; however, the present experiment was not designed explicitly to test this hypothesis. The theory also assumes that fragment relative growth rates remain constant, but this is sure to be violated over long periods of time. The implications of changes in fragment relative growth rates with time need to be investigated and should provide greater insight into clonal plant biology.

The second hypothesis that can be derived from the current results and the theoretical developments of Chesson and Peterson (in press) is that temporal variation in the spatial pattern of water availability will maintain the net benefit of physiological integration at a high level. This hypothesis comes from the discussion in Chesson and Peterson (in press) on alternating environmental conditions and suggests that physiological integration may provide the highest fitness benefits in spatio-temporally variable environments. In such an environment the net benefit depends on the frequency of environmental change compared with the rate of decline in the net benefit under a constant environmental pattern. If the system used in the current experiment was subjected to spatio-temporal variation in water availability, a frequency of alternating conditions equal to 21 days would likely be sufficient to maintain the maximum net benefit of physiological integration because the time dependence of the net benefit in the present experiment was small.

\section{ACKNOWLEDGEMENTS}

This research was supported by the Research School of Biological Sciences, Australian National University, while A. G. Peterson was the recipient of an Australian Commonwealth Government Postgraduate Research Award. We would like to thank Marilyn Ball, Julian Ash and Sandra Lavorel for valuable comments and suggestions during all stages of this research. Peter Alpert, Josef Stuefer, Michael Hutchings and an anonymous reviewer provided important comments on an earlier version of this manuscript. Thanks also go to Natalie 
Hocking for assistance in the field and with the laborious job of measuring plants.

\section{REFERENCES}

Alpert P. \& Mooney H. A. (1986) Resource sharing among ramets in the clonal herb, Fragaria chiloensis. Oecologia 70, 227-33.

Alpert P. \& Stuefer J. F. (1997) Division of labour in clonal plants. In: The Ecology and Evolution of Clonal Plants (eds H. de Kroon \& J. van Groenendael) pp. 137-54. Backhuys Publishers, Leiden, The Netherlands.

Bradford K. J. \& Hsiao T. C. (1982) Physiological responses to moderate water stress. In: Encyclopedia of Plant Physiology, Vol. 12B (eds O. L. Lange, P. S. Nobel, C. B. Osmond \& H. Ziegler) pp. 263-324. Springer-Verlag, Berlin.

Buss L. W. (1985) The uniqueness of the individual revisited. In: Population Biology and Evolution of Clonal Organisms (eds J. B. C. Jackson, L. W. Buss \& R. E. Cook) pp. 467-505. Yale University Press, New Haven.

Cain M. L. \& Damman H. (1997) Clonal growth and ramet performance in the woodland herb, Asarum canadense. F. Ecol. 85, 883-97.

Caraco T. \& Kelly C. K. (1991) On the adaptive value of physiological integration in clonal plants. Ecology 72, 81-93.

Carlsson B. A. \& Callaghan T. V. (1994) Impact of climate change factors on the clonal sedge Carer bigelowii: Implications for population growth and vegetative spread. Ecography 17, 321-30.

Caswell H. (1985) The evolutionary demography of clonal reproduction. In: Population Biology and Evolution of Clonal Organisms (eds J. B. C. Jackson, L. W. Buss \& R. E. Cook) pp. 187-244. Yale University Press, New Haven.

Chesson P. \& Peterson A. G. (in press) The quantitative assessment of the benefits of physiological integration in clonal plants. Evol Ecol Res.

Cook R. E. (1985) Growth and development in clonal plant populations. In: Population Biology and Evolution of Clonal Organisms (eds J. B. C. Jackson, L. W. Buss \& R. E. Cook) pp. 259-96. Yale University Press, New Haven.

Dale M. P. \& Causton D. R. (1992) The ecophysiology of Veronica chamaedrys, V. montana and V. officinalis. I. Light quality and light quantity. F. Ecol. 80, 483-92.

de Kroon H., Fransen B., van Rheenen J. W. A., van Dijk A. \& Kreulen R. (1996) High levels of inter-ramet water translocation in two rhizomatous Carex species, as quantified by deuterium labelling. Oecologia 106, 73-84.

de Kroon H., van der Zalm E., van Rheenen J. W. A., van Dijk A. \& Kreulen R. (1998) The interaction between water and nitrogen translocation in a rhizomatous sedge (Carex flacca). Oecologia 116, 38-49.

Eriksson O. (1989) Seedling dynamics and life histories in clonal plants. Oikos 55, 231-8.

Eriksson O. \& Jerling L. (1990) Hierarchical selection and risk spreading in clonal plants. In: Clonal Growth in Plants: Regulation and Function (eds J. van Groenendael \& H. de Kroon) pp. 79-94. SPD Academic Publishing, The Hague, The Netherlands.

Erschbamer B., Buratti U. \& Winkler J. (1998) Long-term population dynamics of two Carer curvula species in the Central Alps on native and alien soils. Oecologia 115, 114-19.

Evans G. C. (1972) The Quantitative Analysis of Plant Growth. Blackwell Scientific Publications, Oxford.
Evans J. P. (1991) The effect of resource integration on fitness related traits in a clonal dune perennial, Hydrocotyle bonariensis. Oecologia 86, 268-75.

Evans J. P. \& Whitney S. (1992) Clonal integration across a salt gradient by a nonhalophyte, Hydrocotyle bonariensis (Apiaceae). Am. F. Bot. 79, 1344-7.

Fagerström T. (1992) The meristem-meristem cycle as a basis for defining fitness in clonal plants. Oikos 63, 449-53.

Goldberg D. E. (1988) Response of Solidago canadensis clones to competition. Oecologia 77, 357-64.

Hara T. \& Herben T. (1997) Shoot growth dynamics and sizedependent shoot fate of a clonal plant, Festuca rubra, in a mountain grassland. Res. Popul. Ecol. 39, 83-93.

Harper J. L. (1981) The concept of population in modular organisms. In: Theoretical Ecology (ed. R. M. May) pp. 53-77. Sinauer, Sunderland, MA.

Harper J. L. (1985) Modules, branches, and the capture of resources. In: Population Biology and Evolution of Clonal Organisms (eds J. B. C. Jackson, L. W. Buss \& R. E. Cook) pp. 1-33. Yale University Press, New Haven.

Hunt R. \& Bazzaz F. A. (1980) The biology of Ambrosia trifida L. V. Response to fertilizer, with growth analysis at the organismal and sub-organismal levels. New. Phytol. 84 $113-21$.

Hutchings M. J. (1983) Shoot performance and population structure in pure stands of Mercurialis perennis L., a rhizomatous perennial herb. Oecologia 58, 260-4.

Keith H. (1991) Fire, Nitrogen Cycling and Eucalypt Growth. PhD Thesis, Australian National University, Canberra.

Laterra P., Deregibus V. A. \& Maceira N. O. (1997) Demographic variability in tiller populations of two perennial pampa grasses. F. Veg. Sci. 8, 369-76.

Lau R. R. \& Young D. R. (1988) Influence of physiological integration on survivorship and water relations in a clonal herb. Ecology 69, 215-19.

Lindman H. R. (1992) Analysis of Variance in Experimental Design. Springer-Verlag, New York.

Manly B. F. J. (1997) Randomization, Bootstrap and Monte Carlo Methods in Biology, 2nd edn. Chapman \& Hall, London.

Mendoza A. \& Franco M. (1998) Sexual reproduction and clonal growth in Reinhardtia gracilis (Palmae), an understory tropical palm. Am. F. Bot. 85, 521-7.

Nault A. \& Gagnon D. (1993) Ramet demography of Allium tricoccum, a spring ephemeral, perennial forest herb. F. Ecol. 81, 101-19.

Newell S. J., Solbrig O. T. \& Kincaid D. T. (1981) Studies on the population biology of the genus Viola. III. The demography of Viola blanda and Viola pallens. F. Ecol. 69, 997-1016.

Novoplansky A., Cohen D. \& Sachs T. (1989) Ecological implications of correlative inhibition between plant shoots. Physiol. Plant. 77, 136-40.

Okland R. H. (1995) Population biology of the clonal moss Hylocomium splendens in Norwegian boreal spruce forests. I. Demography. F. Ecol. 83, 697-712.

Pedersen B. (1995) An evolutionary theory of clonal senescence. Theor. Popul. Biol. 47, 292-320.

Pedersen B. \& Tuomi J. (1995) Hierarchical selection and fitness in modular and clonal organisms. Oikos 73, 167-80.

Peterson A. G. (1996) Ecological and evolutionary implications of physiological integration in clonal plants. PhD Thesis, Australian National University, Canberra.

Piqueras J. \& Klimes L. (1998) Demography and modelling of clonal fragments in the pseudoannual plant Trientalis europaea L. Plant Ecol. 136, 213-27. 
Pitelka L. F. \& Ashmun J. W. (1985) Physiology and integration of ramets in clonal plants. In: Population Biology and Evolution of Clonal Organisms (eds J. B. C. Jackson, L. W. Buss \& R. E. Cook) pp. 399-435. Yale University Press, New Haven.

Sackville Hamilton N. R., Schmid B. \& Harper J. L. (1987) Life-history concepts and the population biology of clonal organisms. Proc. R. Soc. Lond. B. Biol. Sci. 232, 35-57.

Salzman A. G. \& Parker M. A. (1985) Neighbors ameliorate local salinity stress for a rhizomatous plant in a heterogeneous environment. Oecologia 65, 273-7.

Shimizu T., Hatanaka Y., Zentoh H. et al. (1998) The role of sexual and clonal reproduction in maintaining population in Fritillaria camtschatcensis (L.) Ker-Gawl. (Liliaceae). Ecol. Res. 13, 27-39.

Sibly R. M. (1989) What evolution maximises. Funct. Ecol. 3, 129-35.

Silvertown J., Franco M., Pisanty I. \& Mendoza A. (1993) Comparative plant demography: Relative importance of life cycle components to the finite rate of increase in woody and herbaceous perennials. F. Ecol. 81, 465-76.

Stearns S. C. (1992) The Evolution of Life Histories. Oxford University Press, Oxford.

\section{APPENDIX I}

The material in this appendix is intended as an easily accessible summary of the relevant formulae in Peterson (1996) and Chesson and Peterson (in review). Full derivations can be found by consulting these references.

Net benefit of physiological integration

For situations when initial fragment masses are similar, the genet RGR is

$$
\frac{1}{t} \ln \left\{\frac{1}{n} \Sigma_{c} e^{R c t}\right\}
$$

where $R_{c}$ is the RGR of the fragment experiencing environmental condition $c(c=+-,-+,++$ or --$), n$ is the number of different environmental conditions, and $t$ is the duration of time over which measurements are made. Evaluating this formula for the homogeneous treatments and subtracting it from that for the heterogeneous treatments gives the net benefit of physiological integration over an environmental boundary:

$$
\frac{1}{t} \ln \left\{\frac{1}{2}\left(e^{R-+t}+e^{R+-t}\right)\right\} \frac{1}{t}-\ln \left\{\frac{1}{2}\left(e^{R-t}+e^{R++t}\right)\right\}
$$

This expression is general and does not depend on the assumption of exponential growth; however, it does show that the net benefit of physiological integration is dependent on time. The net benefit for short periods of time is obtained by taking the mathematical limit of equation 2 as $t \rightarrow 0$ to obtain

$$
\text { NetBen }=\frac{R_{-+}+R_{+-}}{2}-\frac{R_{--}+R_{++}}{2}
$$

Stoner D. S. (1989) Fragmentation: A mechanism for the stimulation of genet growth rates in an encrusting colonial ascidian. Bull. Mar. Sci. 45, 277-87.

Stuefer J. F., de Kroon H. \& During H. J. (1996) Exploitation of environmental heterogeneity by spatial division of labour in a clonal plant. Funct. Ecol. 10, 328-34.

Stuefer J. F., During H. J. \& de Kroon H. (1994) High benefits of clonal integration in two stoloniferous species, in response to heterogeneous light environments. $\mathcal{F}$. Ecol. 82, 511-18.

Tietema T. \& van der Aa F. (1981) Ecophysiology of the sand sedge Carex arenaria L. III. Xylem translocation and the occurrence of patches of vigorous growth within the continuum of a rhizomatous plant system. Acta Bot. Neerl. 30, 183-9.

Wijesinghe D. K. \& Whigham D. F. (1997) Costs of producing clonal offspring and the effects of plant size on population dynamics of the woodland herb Uvularia perfoliata (Liliaceae). F. Ecol. 85, 907-19.

Wikberg S. (1995) Fitness in clonal plants. Oikos 72, 293-7.

Wilkinson L. (1992) systat: The System for Statistics. SYSTAT, Evanston, IL.

Worley A. C. \& Harder L. D. (1996) Size-dependent resource allocation and costs of reproduction in Pinguicula vulgaris (Lentibulariaceae). F. Ecol. 84, 195-206.

NetBen has a very simple and intuitive interpretation: there is a net benefit of physiological integration between heterogeneous conditions if the average RGR of genet fragments growing under heterogeneous conditions exceeds the average RGR of genet fragments growing under homogeneous conditions. NetBen can be thought of as the instantaneous net benefit of physiological integration, whereas equation 2 gives the net benefit over a defined interval. For short intervals of time equation 2 exceeds NetBen by an amount approximated by

$$
\frac{1}{2}\left[\left(\frac{R_{-+}-R_{+-}}{2}\right)^{2}-\left(\frac{R_{--}-R_{++}}{2}\right)^{2}\right] t
$$

Equation 4 applies when genet fragments have constant RGR, which is a reasonable assumption over short intervals of time. More importantly, equation 4 increases linearly with time and can be used both as a correction to NetBen for small values of $t$ and also as an indication of how the benefits of physiological integration change with the time interval involved.

\section{Costs and benefits within a genet fragment}

To quantify the costs and benefits of physiological integration within a genet fragment we calculated the component RGR, CRGR, for fragment sections following Hunt and Bazzaz (1980):

$$
\frac{\left(W_{c i}(t)-W_{c i}(0)\right)\left(\ln W_{c}(t)-\ln W_{c}(0)\right)}{t\left(W_{c}(t)-W_{c}(0)\right)}
$$


Here $W_{c}$ is the dry mass of the genet fragment and $W_{c i}$ is the dry mass of the $i$ th section (component) of that fragment. This expression assumes an approximately linear relationship between $W_{c}$ and $W_{c i}$. Component RGR values are additive and the sum of the CRGR values for a genet fragment equals the RGR of the fragment. Given the CRGR values for the sections of a genet fragment, NetBen becomes

$$
\text { NetBen }=\frac{P_{-+}+O_{-+}+P_{+-}+O_{+-}}{2}-\frac{P_{--}+O_{--}+P_{++}+O_{++}}{2}
$$

where $P$ and $O$ refer to the CRGR values of parent and offspring sections of a genet fragment experiencing the conditions indicated by the subscripts. Note that $P_{c}+O_{c}=R_{c}$. From these CRGR values we can define cost and benefit measures at the sectional level following the logic of Salzman and Parker (1985). For parent sections, these are

$$
\operatorname{Cost} P=P_{++}-P_{+-}
$$

which defines the cost, in terms of a changed CRGR, that an unstressed parent section experiences due to its connection to a stressed section. The benefit to a stressed parent section from its connection to an unstressed partner is defined as

$$
\operatorname{BenP}=P_{-+}-P_{--}
$$

Substitution of $O$ for $P$ above leads to the corresponding definitions for $\mathrm{Cost} O$ and $\mathrm{BenO}$. Combining these costs and benefits leads back to NetBen:

$$
\begin{gathered}
\text { NetBen }=1 / 2 \operatorname{BenP}+1 / 2 \operatorname{BenO}- \\
1 / 2 \operatorname{CostP}-1 / 2 \operatorname{Cos} \mathrm{O}
\end{gathered}
$$

These costs and benefits are defined in such a way that a net benefit occurs at the level of the genet simply if total sectional benefits exceed total sectional costs.

NetBen can also be split into two additive com- ponents giving net benefit contributions due to parent and offspring sections:

$$
N e t B e n=N e t B e n P+N e t B e n O,
$$

where

$$
\operatorname{NetBenP}=\frac{P_{-+}+P_{+-}}{2}-\frac{P_{--}+P_{++}}{2}
$$

and

$$
N e t B e n O=\frac{O_{-+}+O_{+-}}{2}-\frac{O_{--}+O_{++}}{2}
$$

\section{Null hypothesis of no physiological integration}

When physiological integration is absent then sections should grow independently of one another. In the experimental situation where the initial size of sections are approximately equal, NetBen can be expressed as

$$
\begin{aligned}
& \frac{\left(R_{p-+}-R_{p--}\right)+\left(R_{0+-}-R_{0--}\right)-}{4} \\
& \frac{\left(R_{p++}-R_{p+-}\right)+\left(R_{0++}-R_{0-+}\right)}{4}
\end{aligned}
$$

Here $R_{P c}$ and $R_{O c}$ are the RGR values of the parent and offspring sections, respectively, not their component RGR values. In this expression, NetBen divides neatly into section-level costs and benefits in terms of RGR values of genet fragments, for example $\operatorname{BenP}=\left(R_{p-+}-\right.$ $\left.R_{p--}\right) / 2$. With no physiological integration, the costs and benefits represented in equation 13 are all zero (the RGR of a section does not depend on the environment of its partner), and this expression for NetBen is then equal to zero. Equation 13 is used to test the null hypothesis of no physiological integration when the assumption of exponential growth of genet fragments fails. 